\title{
EVALUATION OF A TWO-FORMANT SPEECH-PROCESSING STRATEGY FOR A MÚLTICHANNEL COCHLEAR PROSTHESIS
}

\author{
R. C. Dowell, BSc, Dip Aud: P. M. Seligman, BE, PhD; P. J. Blamey, PhD; G. M. Clark, PhD, Fracs
}

Initial results with the two-formant speech-processing strategy (FoFIF2) confirm the advantage of a multichannel cochlear prosthesis capable of stimulating at different sites within the cochlea. The successful presentation of two spectral components by varying the place of stimulation leads to the possibility of presenting further spectral information in this manner. Because virtually all multichannel implant patients demonstrate good "place" (electrode site) discrimination, these more refined coding strategies should lead to benefits for the majority of implantees. Already, with the F0FIF2 strategy, we have a system that appears to provide some effective auditory-alone communication ability for the average patient.

Since clinical trials began with the Nucleus 22-channel cochlear prosthesis in 1982, the same speech-processing strategy has been used for all patients. This strategy codes the amplitude of speech signals onto the current level of stimulation, the fundamental frequency or voice pitch onto the rate of stimulation, and the second formant (or front cavity resonance) onto the place of stimulation. ${ }^{1}$ These acoustic features were chosen as conveying the most intelligibility, given that only three features are to be coded. ${ }^{2}$ The optimal method of coding these parameters was determined from intensive psychophysical research on a small number of multichannel implant patients. ${ }^{3,4}$ Subsequent clinical testing has indicated that all three of these acoustic parameters are conveyed effectively to patients ${ }^{5}$ and that the speech-processing strategy provides some understanding of unknown speech material without lipreading for almost all patients. ${ }^{6}$ Results to date show a mean score for open set standardized sentence material of $40 \%$ for patients with 12 months' experience with the Nucleus prosthesis (R. C. Dowell, et al, unpublished observations).

However, it is known that full speech intelligibility is not possible with second formant (F2) information only, and that the first formant $(\mathrm{Fl})$ is also critical to speech understanding. Thus, if an effective method could be found to present Fl information without affecting the other acoustic parameters, the speech understanding of patients could be improved significantly. This paper presents some initial results with a new speech-processing strategy that provides $\mathrm{F}$ l information in addition to the fundamental frequency (F0) and F2.

\section{CODING STRATEGY}

Psychophysical investigations have shown that electrical stimuli presented at two separate sites within the cochlea simultaneously can elicit two-component hearing sensations in deaf patients. ${ }^{7}$ This suggests that it may be possible to code two spectral components of running speech using such two-electrode stimuli. With the present system (F0F2), only one site within the cochlea is stimulated at any particular time. The place of stimulation, and hence the pitch of the elicited sound sensation, varies with the F2 of the signal. The new coding scheme (F0F1F2) uses an estimate of $F 1$ to control the position of a second stimulation site within the cochlea. This strategy has been implemented by modifying a number of standard speech processors.

One of the problems of simultaneous electrical stimulation using more than one electrode pair is current interaction. ${ }^{8}$ The two electrical signals can combine causing large fluctuations in the perceived loudness depending on the relative positions and amplitude of the signals. In implementing the new coding strategy, this problem has been avoided by offsetting the two pulse trains by $800 \mu \mathrm{s}$. The Nucleus cochlear prosthesis typically uses pulse widths of $200 \mu \mathrm{s} /$ phase, which means that the two currents can never interact because they do not overlap temporally. The perceived loudness of two-electrode stimuli can, in this way, be controlled easily and requires only a knowledge of each individual electrode's loudness growth function (ie, the same information required for the standard F0F2 strategy). If current interaction was not avoided in this way, loudness information for each of the possible 200 combinations of electrodes would be needed. The large amount of psychophysical testing required would make such a system clinically impractical.

\section{METHOD}

To assess the effectiveness of the F0F1F2 strategy seven patients were fitted with new programmable speech processors modified for the presentation of $\mathrm{F} 1$ information. ${ }^{9}$ These patients had been using $\mathrm{F} 0 \mathrm{~F} 2$ strategies for periods ranging from 3 to 18 months. They were not selected in any way other than by their availability for testing and the ability of all seven patients to discriminate percepts elicited at different electrode sites within the cochlea (approximately $10 \%$ of patients are unable to discriminate electrodes because of early onset of deafness or degeneration of cochlear structures). Patients were assessed with the FoF2 strategy using the Central Institute for the Deaf (CID) open set everyday sentence test. This was presented live voice at average peak levels of $75 \mathrm{dBA}$. Patients had not been trained on this material and no contextual clues were given. Each patient then had 2 to 3 weeks of take-home experience with the FoF1F2 strategy and was retested with a different list of CID sentences. In addition, four of the patients were addressed on both occasions using continuous discourse tracking with auditory input alone. Tracking rates were assessed over a 10 -minute period. This task required the patients to repeat verbatim an unknown text read out loud by a clinician. Responses were corrected using a hierarchy of strategies; however, no lipreading or visual cues were used at any time.

\section{RESULTS}

The CID sentence test scores for each patient are shown in Table 1. All seven patients scored substantially better on this test with the new F0F1F2 strategy. The mean improvement was highly significant for the group as a whole (mean difference $=32.4 \%, t=5.79, \mathrm{df}=6, \mathrm{p}<0.01$ ). The mean scores were $30.4 \%$ for F0F2 and $62.9 \%$ for F0F1F2. 
TABLE 1. CENTRAL INSTITUTE FOR THE DEAF EVERYDAY SENTENCE TEST

\begin{tabular}{cccc}
\hline \hline \multirow{2}{*}{ Patient } & \multicolumn{2}{c}{ Percent of Key Words Correct } & \\
\cline { 2 - 4 } & Fo/ 2 & Fo/F1/F2 & Difference \\
\hline 1 & 54 & 90 & +36 \\
2 & 38 & 70 & +32 \\
3 & 31 & 54 & +23 \\
4 & 16 & 62 & +46 \\
5 & 10 & 26 & +16 \\
6 & 20 & 38 & +18 \\
7 & 44 & 100 & +56 \\
Mean & 30.4 & 62.9 & +32.4 \\
$t=5.79 . \mathrm{df}=6, \mathrm{p} 0.01$. & &
\end{tabular}

Scores for the continuous discourse tracking test (Table 2) also showed large improvements for each patient with the new strategy. Mean tracking rates were 11.75 words per minute (wpm) for F0F2and $30.5 \mathrm{wpm}$ for F0F1F2, and this was highly significant (mean difference $=18.75 \mathrm{wpm}$, $t=7.55, \mathrm{df}=3, \mathrm{p}<0.01$ )

\section{DISCUSSION}

These results indicate that after a relatively small amount of experience with the F0F1F2 strategy, patients show substantial improvement in speech understanding without lipreading. The mean sentence score obtained with the new scheme of $62.9 \%$ is enough to allow effective interactive auditory communication for all of these patients. Not only the best patients improve (eg, patients 1 and 2), but patients performing only at average levels for the $\mathrm{F} 0 \mathrm{~F} 2$ strategy are improved to the extent that speech tracking at reasonable rates is possible without lipreading (eg, patients 4 and 7 ).

These results are consistent with those obtained with an acoustic model of the cochlear prosthesis. ${ }^{10}$ The acoustic model studies indicated that better speech recognition was obtained at the continuous discourse level because of the addition of $F 1$ information and that this information improved scores for vowel recognition but had little effect on consonant recognition. Further investigations are now being undertaken with implant patients to evaluate these additional factors relating to the new strategy.

It may come as something of a surprise that the patients' subjective reactions to the new speech-processing strategy were at first generally negative. They immediately identified two components in speech input and in most cases interpreted the lower pitch component (F1 signal) as background noise interfering with the voice. It appears that after many months of listening experience with the FoF2
TABLE 2. CONTINUOUS DISCOURSE TRACKING RATES: AUDITORY INPUT ONLY

\begin{tabular}{cccc}
\hline & \multicolumn{2}{c}{ Words per Minute } & \\
\cline { 2 - 4 } Patient & Fo/F2 & Fo/F1/F2 & Difference \\
\hline 1 & 24 & 42 & +18 \\
2 & 13 & 29 & +16 \\
4 & 5 & 20 & +15 \\
7 & 5 & 31 & +26 \\
Mean & 11.75 & 30.5 & +18.75
\end{tabular}

$t=7.55, \mathrm{df}=3, \mathrm{i},<0.01$.

strategy, the patient's attention was directed to the F2 component of the signal to the exclusion of Fl. However, after a short time, all patients adapted to the new scheme and reported improvement in the clarity and naturalness of speech, better recognition of environmental sounds, and improved communication ability, particularly without lipreading.

\section{REFERENCES}

1. Tong YC, Clark GM, Seligman PM, Patrick JF. Speech processing for a multiple electrode cochlear implant hearing prosthesis. J Acoust Soc Am 1980;68:1897-9.

2. Liberman AM, Harris KF, Hoffman HS, Griffith EC. The discrimination of speech sounds within and across phoneme boundaries. J Exp Psychol 1957;54:358-68.

3. Tong YC, Clark GM, Blamey PJ, Busby PA, Dowell RC. Psychophysical studies for two multiple-channel implant patients. J Acoust Soc Am 1982;71:153-60.

4. Tong YC, Blamey PJ, Dowell RC, Clark GM. Psychophysical studies evaluating the feasibility of a speech processing strategy for a multiple channel cochlear implant. J Acoust Soc Am 1983; 74:73-80.

5. Dowell RC, Tong YC, Blamey PJ, Clark GM. Psychophysics of multiple-channel stimulation. In: Schindler RA, Merzenich MM, eds. Cochlear implants. New York: Raven Press, 1985:283-90.

6. Dowell RC, Martin LFA. Clark GM, Brown AM. Results of a preliminary clinical trial on a multiple-channel cochlear prosthesis. Ann Otol Rhinol Laryngol 1985;94:244-50.

7. Tong YC, Dowell RC, Blamey PJ, Clark GM. Two component bearing sensations produced by two-electrode electrical stimulation in the cochlea of a deaf patient. Science 1983;219:993-4.

8. White MW, Merzenich MM, Gardi JN. Multichannel cochlear implants: channel interactions and processor design. Arch Otolaryngol 1984:110:493-501.

9. Seligman PM. Speech-processing strategies and their implementation. Ann Otol Rhinol Laryngol 1987;96(suppl 128):71-4

10. Blamey PJ. Martin LFA, Clark GM. A comparison of three speech coding strategies using an acoustic model of a cochlear implant. J Acoust Soc Am 1985;77:209-17. 


\section{University Library}

\section{- M M N E R VA A gateway to Melbourne's research publications}

Minerva Access is the Institutional Repository of The University of Melbourne

Author/s:

Dowell, R. C.;Seligman, P. M.;Blamey, P. J.;Clark, Graeme M.

Title:

Evaluation of a two-formant speech-processing strategy for a multichannel cochlear prosthesis

Date:

1987

\section{Citation:}

Dowell, R. C., Seligman, P. M., Blamey, P. J., \& Clark, G. M. (1987). Evaluation of a twoformant speech-processing strategy for a multichannel cochlear prosthesis. Annals of Otology, Rhinology \& Laryngology, January-February, 96(1, part 2, suppl.128), 132-133.

Persistent Link:

http://hdl.handle.net/11343/27246 